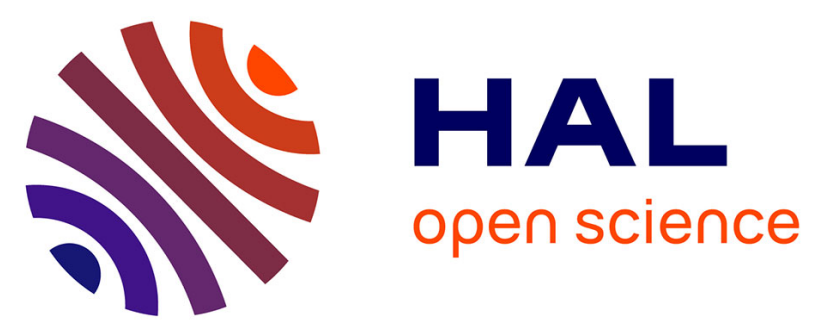

\title{
Efficiency of coseismic ionospheric perturbations in identifying crustal deformation pattern: Case study based on M w 7.3 May Nepal 2015 earthquake
}

\author{
Mala Bagiya, A. Sunil, P. Sunil, K. Sreejith, Lucie Rolland, D. Ramesh
}

\section{To cite this version:}

Mala Bagiya, A. Sunil, P. Sunil, K. Sreejith, Lucie Rolland, et al.. Efficiency of coseismic ionospheric perturbations in identifying crustal deformation pattern: Case study based on M w 7.3 May Nepal 2015 earthquake. Journal of Geophysical Research Space Physics, 2017, 122 (6), pp.6849 - 6857. 10.1002/2017JA024050 . hal-01734521

\author{
HAL Id: hal-01734521 \\ https://hal.science/hal-01734521
}

Submitted on 18 Nov 2021

HAL is a multi-disciplinary open access archive for the deposit and dissemination of scientific research documents, whether they are published or not. The documents may come from teaching and research institutions in France or abroad, or from public or private research centers.
L'archive ouverte pluridisciplinaire HAL, est destinée au dépôt et à la diffusion de documents scientifiques de niveau recherche, publiés ou non, émanant des établissements d'enseignement et de recherche français ou étrangers, des laboratoires publics ou privés. 


\section{Journal of Geophysical Research: Space Physics}

\section{RESEARCH ARTICLE \\ 10.1002/2017JA024050 \\ Key Points: \\ - InSAR derived surface deformation \\ Efficiency of coseismic ionospheric perturbations in identifying crustal deformation pattern: Case study based on $M_{w} 7.3$ May Nepal 2015 earthquake} map and the modeled coseismic slip associated with the $M_{w} 7.3$ May Nepal 2015 earthquake are presented

- Phase cancelation effects on the seismic induced ionospheric perturbations for various receiver satellite line-of-sight configurations

- Role of nontectonic forcing mechanisms while identifying ground source pattern using associated ionospheric perturbations

\section{Correspondence to:}

M. S. Bagiya,

bagiyamala@gmail.com;

mala@iigs.iigm.res.in

\section{Citation:}

Bagiya, M. S., A. S. Sunil, P. S. Sunil, K. M. Sreejith, L. Rolland, and D. S. Ramesh (2017), Efficiency of coseismic ionospheric perturbations in identifying crustal deformation pattern: Case study based on $M_{w} 7.3$ May Nepal 2015 earthquake, J. Geophys. Res. Space Physics, 122, 6849-6857, doi:10.1002/ 2017JA024050.

\section{Received 17 FEB 2017}

Accepted 6 JUN 2017

Accepted article online 20 JUN 2017

Published online 27 JUN 2017

\author{
Mala S. Bagiya' ${ }^{(D}$, A. S. Sunil' ${ }^{1}$, P. S. Sunil' ${ }^{1}$, K. M. Sreejith ${ }^{2}$ (D) Lucie Rolland ${ }^{3}$, and D. S. Ramesh ${ }^{1}$ \\ ${ }^{1}$ Indian Institute of Geomagnetism (DST), Navi Mumbai, India, ${ }^{2}$ Geosciences Division, Space Applications Center (ISRO), \\ Ahmedabad, India, ${ }^{3}$ Université Côte d'Azur, OCA, CNRS, IRD, Géoazur, Sophia-Antipolis, Valbonne, France
}

\begin{abstract}
The amplitude asymmetry and initial polarity of seismic induced ionospheric perturbations around the epicenter are considered to be important in providing information about the rupture propagation and related vertical surface deformation. To comprehend this, we study ionospheric perturbations related to the 12 May 2015, $M_{w} 7.3$ Nepal earthquake. We model the coseismic slip associated with the event using the interferometric synthetic aperture radar derived surface deformation data. The ionospheric perturbations associated with the obtained surface deformation are explained in terms of rupture propagation, favorable geomagnetic field-wave coupling, and satellite geometry effects. We discuss the effects of phase cancelation on the perturbation evolution for various receiver satellite line-of-sight configurations invoking an elementary version of satellite geometry factor. The present study thus elucidates further the role of nontectonic forcing mechanisms while identifying ground source pattern using the associated ionospheric perturbations.
\end{abstract}

\section{Introduction}

During shallow earthquakes of large magnitude about $10^{-4}$ to $10^{-5}$ part of the total seismic energy is transferred to nearby atmosphere through mechanical coupling between the Earth and its atmosphere [Lognonne et al., 1998]. The vertical surface deformations originating from the hypocenter oscillate the nearby atmosphere and triggers waves mainly of acoustic frequencies [e.g., Rolland et al., 2011; Sunil et al., 2015, 2016, and references therein]. The upward propagating waves amplify up to $\sim 10^{4}$ times at $\sim 150 \mathrm{~km}$ altitude, to compensate with the exponentially decreasing background neutral density [Artru et al., 2004]. On arrival at ionospheric altitudes, the waves redistribute ionospheric electron density and manifest as electron density enhancement or depletion depending generally upon the incoming wave phase [Astafyeva and Heki, 2009]. These seismic induced ionospheric perturbations are termed as coseismic ionospheric perturbations (CIP) [e.g., Sunil et al., 2016].

The amplitude and initial polarity of CIP are considered to be very useful in characterizing the large dip-slip earthquakes. By analyzing the CIP associated with 2004 Sumatra earthquake, Heki et al. [2006] derived source parameters in terms of rupture propagation speed and lateral extent of rupture. As CIP propagate in the ionosphere, the geomagnetic field, receiver satellite line of sights (LOS), and background ionization restructure the phase and amplitude of CIP. These all can be termed as nontectonic forcings that affect CIP at measurement altitudes. Using a case study of 2015 Illapel earthquake, Chum et al. [2016] reported that the shape and amplitude of CIP may also vary due to the nonlinear behavior of quasi-vertically propagating infrasound waves. Astafyeva and Heki [2009] studied near-field CIP associated with three large events $\left(M_{w}>8\right)$ and linked the initial polarity of CIP with the coseismic surface deformations. Rolland et al. [2013] carried out further analysis of ionospheric perturbations during 2011 Van earthquake of $M_{w} 7.1$ and reported that polarity change of CIP is mainly controlled by the geomagnetic field configuration around the epicenter and not related to the rupture features. Recently, Sunil et al. [2016] were the first to study the azimuthal anisotropy in the spatial variations of near field CIP related to the $M_{w} 7.825$ April 2015 Nepal earthquake. They emphasized the combined effects of tectonic forcing and favorable geomagnetic field-acoustic wave coupling in evolving significant CIP toward east-southeast of the epicenter while the geomagnetic field-wave coupling observed to distort the CIP in north of the epicenter in their study.

In addition to the geomagnetic field-wave coupling, the wave phase cancelation effects due to the varying receiver satellite LOS, i.e., satellite geometry, also play crucial roles in facilitating the surface deformations 
to imprint in the ionosphere during an earthquake. There are few studies reported on the effects of phase cancelation on CIP evolution [e.g., Heki and Ping, 2005; Grawe and Makela, 2015, and references therein]. In the present study, we bring out the importance of phase cancelation effects during varying receiver satellite LOS in an elementary manner and proceed to evaluate the competing effects of tectonic and nontectonic origin on CIP evolution for the recent $M_{w} 7.3$, Nepal earthquake occurred as a result of low-angle reverse faulting at a depth of $\sim 15 \mathrm{~km}$ associated with Main Himalayan Thrust (MHT) struck on 12 May 2015 at 07:05 UTC [National Earthquake Information Center-U.S. Geological Survey (NEIC-USGS), 2015]. Our analyses reveal that despite the southeast oriented rupture propagation and favorable geomagnetic field-wave coupling to the south of the epicenter, significant CIP are registered in southwest compared to that in southeast. This would have remained quite intriguing without evaluating the nontectonic forcing owing to varying receiver satellite LOS effect. The significant CIP in southwest are explained based on the satellite geometry factor (SGF) derived in this study, thus emphasizing the importance of wave phase cancelation effect on CIP evolution.

\section{Crustal Deformation and Rupture Propagation}

The $M_{w} 7.3$ event is imaged using interferogram generated from ALOS-2 satellite data between 5 and 17 May 2015 [Lindsey et al., 2015] operated by the Japan Aerospace Exploration Agency. The obtained surface deformation map (Figure 1a) suggests about -0.5 to $0.75 \mathrm{~m}$ deformation along the line of sight of the satellite. The deformation pattern is elliptical, extending slightly in south-southeast direction, and the rupture is more compact compared to the 25 April 2015, $M_{w} 7.8$ event. We inverted interferometric synthetic aperture radar (InSAR) data to derive coseismic slip on the causative fault of the earthquake assuming linear superposition of rectangular dislocations in an elastic half-space [Okada, 1985]. As the geometry of the MHT is important to understand the slip distribution, Sreejith et al. [2016] approximated the fault geometry of MHT which reaches the surface at Main Frontal Thrust (MFT) by four rectangular fault segments representing the frontal ramp, southern flat, midcrustal ramp, and northern flat in the Nepal Himalayas for the inversion of the $M_{w}=7.8$ event. Considering the compact source for the $M_{w}=7.3$ event, the model fault is restricted to three segments excluding the frontal ramp.

We use the steepest descent method iterative algorithm [Wang et al., 2013] for the constrained least squares optimization to solve for the dip-slip and strike-slip components. The optimum smoothing factor $\left(\gamma^{2}=0.175\right)$ for the inversion was chosen from the trade-off curve between the model roughness and misfit (the $L$ curve). The maximum coseismic slip modeled is about $3.8 \mathrm{~m}$ at a depth of $14 \mathrm{~km}$ (Figure $1 \mathrm{~b}$ ). The corresponding moment released is $1.146 \times 10^{20} \mathrm{Nm}$ that corresponds to a magnitude of $M_{w}=7.31$, which closely agrees with that obtained from seismic waveform inversion $\left(M_{w}\right.$ 7.3) [NEIC-USGS, 2015]. The source model of the $M_{w} 7.3$ event is compact with slip distribution confined to the upper part of the midcrustal ramp on the MHT. It could be seen that most seismic energy due to rupture is propagated in south of the epicenter during 12 May 2015 event.

\section{Ionospheric Observations}

GPS-total electron content (TEC) is an established diagnostic tool to study the temporal and spatial ionospheric variability over various scales [e.g., Rama Rao et al., 2006; Bagiya et al., 2009, and references therein]. Fortunately, the May 2015 Nepal earthquake event was reasonably well constrained with GPS-TEC data available near the rupture area. TEC, at every $30 \mathrm{~s}$, is derived from the dual frequency observations of International Global Navigation Satellite Systems service (IGS) stations, Nepal Geodetic and Indian GPS networks. The Slant TEC (sTEC) estimation method is followed as given in Sunil et al. [2016]. The sTEC is further detrended using polynomial with degree up to 7 which provides high-pass filter to TEC perturbations and suitable to highlight the acoustic originated perturbations. The ionospheric piercing points (IPP) corresponding to each satellite TEC measurements are also estimated at $\sim 330 \mathrm{~km}$ of height which is the peak electron density height at the epicenter derived from IRI-2012. It is verified with the World Data Center (WDC) from geomagnetism, Kyoto, that the 12 May 2015 is a geomagnetically quiet day (planetary $K$ index $=3$, minimum disturbed time storm index $=-32 \mathrm{nT}$ between 1 and 8 UTC), and also, there is no major solar flare around the earthquake onset time (http://www.spaceweather.com/).

The CIP within 800 km surrounding the epicenter are considered as near-field CIP [e.g., Otsuka et al., 2006]. Figure 2a depicts the location of CIP at the respective IPP locations as observed by various GPS satellites 

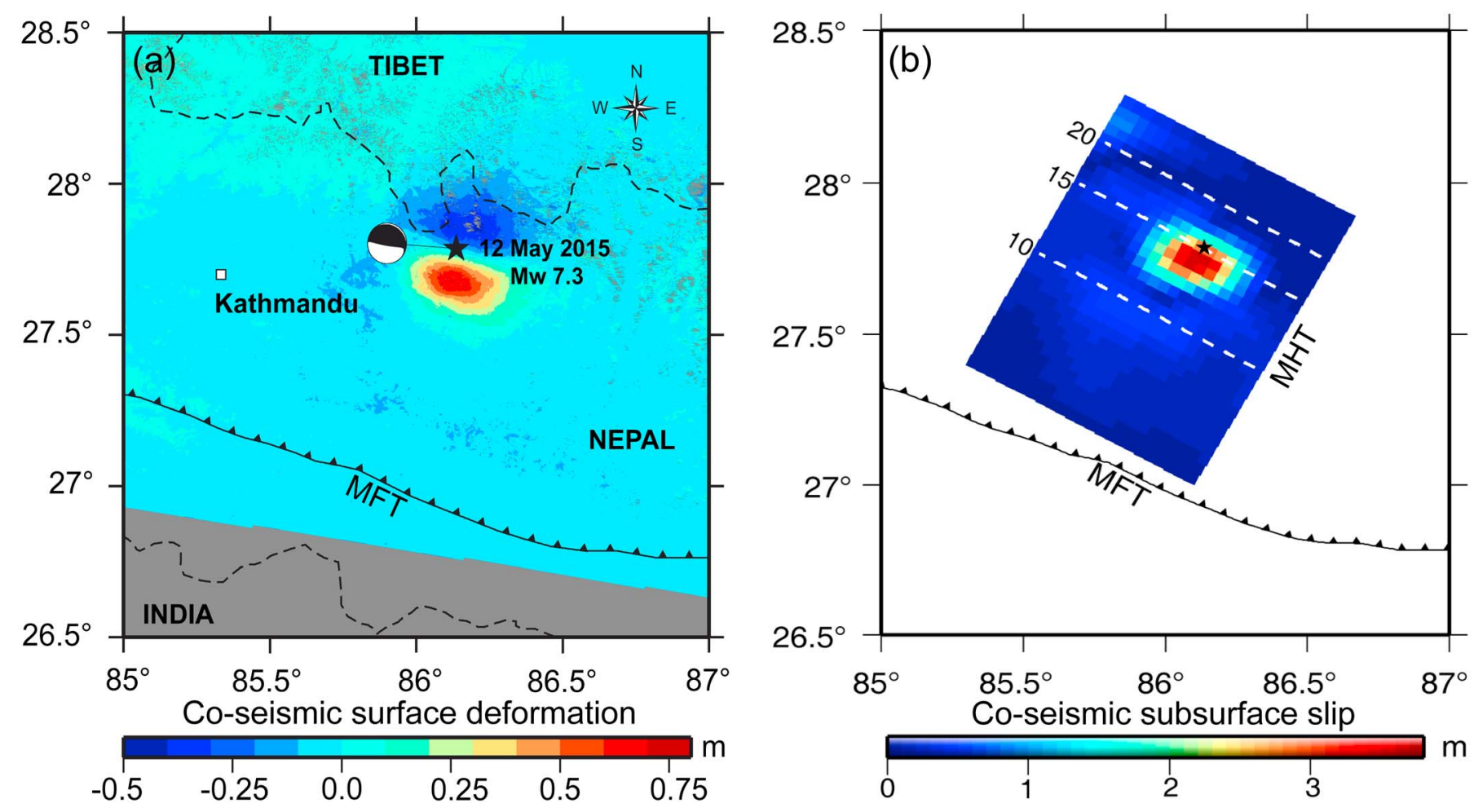

Figure 1. (a) InSAR-derived coseismic crustal deformation map during 12 May $2015 M_{w} 7.3$ Nepal earthquake. Note that the InSAR deformation is along the line of sight of the satellite; positive and negative values mainly indicate uplift and subsidence, respectively. (b) Coseismic slip model of the 12 May $2015 M_{w} 7.3$ Nepal event. The star indicates the earthquake epicenter location and the black line indicates the Main Frontal Thrust (MFT).

(PRN 19, 09, 23, and 27) surrounding the epicenter. The color of the disk shows CIP amplitudes. To understand CIP variability better, we divided the total area into four regions. The land deformation of Figure 1a is reproduced in Figure 2a for the comparative view of surface deformation and CIP amplitude distribution around the epicenter. The CIP signatures are observed within $\sim 8.5$ to $\sim 12 \mathrm{~min}$ of the earthquake onset. It is noticed that maximum of CIP amplitudes observed in region 4. In region 2, TEC observations are available, but since no CIP signatures are observed by any of the PRNs, the region is void in Figure 2a. Figure $2 \mathrm{~b}$ shows CIP evolution in time as observed by PRN 19. In regions 1 and 3, PRN 19 TEC perturbed with less amplitudes mostly with initial phase as depletion while region 4 exhibited significant CIP perturbations with initial phase as an enhancement. Observation from alh2-19, in region 4, showed maximum amplitude of $\sim 1.24$ total electron content unit, $1 \mathrm{TECU}=10^{16} \mathrm{el} \mathrm{m}^{-2}$ (TECU). It could also be noticed that initial positive phase of CIP in region 4 gradually evolved with distance in southwest direction. CIP variability in time from PRN 09, 23, and 27 is shown in Figure 2c. PRN 27 in region 4 captured maximum CIP amplitude at alh2-27( 1.69 TECU). However, regions 1 and 3 witnessed smaller-amplitude CIP. Though the surface deformations mainly occurred in south and southeast (region 3 ) with reference to the epicenter, the significant ionospheric response is seen in the southwest. This peculiar behavior is discussed in terms of the various nontectonic forcing mechanisms as follows.

\section{Geomagnetic Field-Wave Coupling and Background Ionization Variability}

The geomagnetic field-wave coupling mainly controls the propagation of CIP at $F$ region altitudes. When the seismic induced acoustic wave perturbations propagate parallel to the geomagnetic field direction, Lorentz force is least effective and the wave propagation is unaffected. If the wave vector and field direction are perpendicular to each other, then the opposing Lorentz force inhibits the further propagation. To determine the effects of geomagnetic field-wave coupling on the CIP distribution, we have estimated the geomagnetic coupling factor at ionospheric altitude of $\sim 330 \mathrm{~km}$ as, $\mathbf{k} . \mathbf{I}_{\mathbf{b}}$ [Rolland et al., 2011; Sunil et al., 2016]. Here $\mathbf{k}$ is the acoustic wave vector and $\mathbf{I}_{\mathbf{b}}$ is geomagnetic field unit vector. The acoustic wave vector paths originating from the epicenter is derived using acoustic ray tracing method [Calais et al., 1998; Heki and Ping, 2005; 
(a)

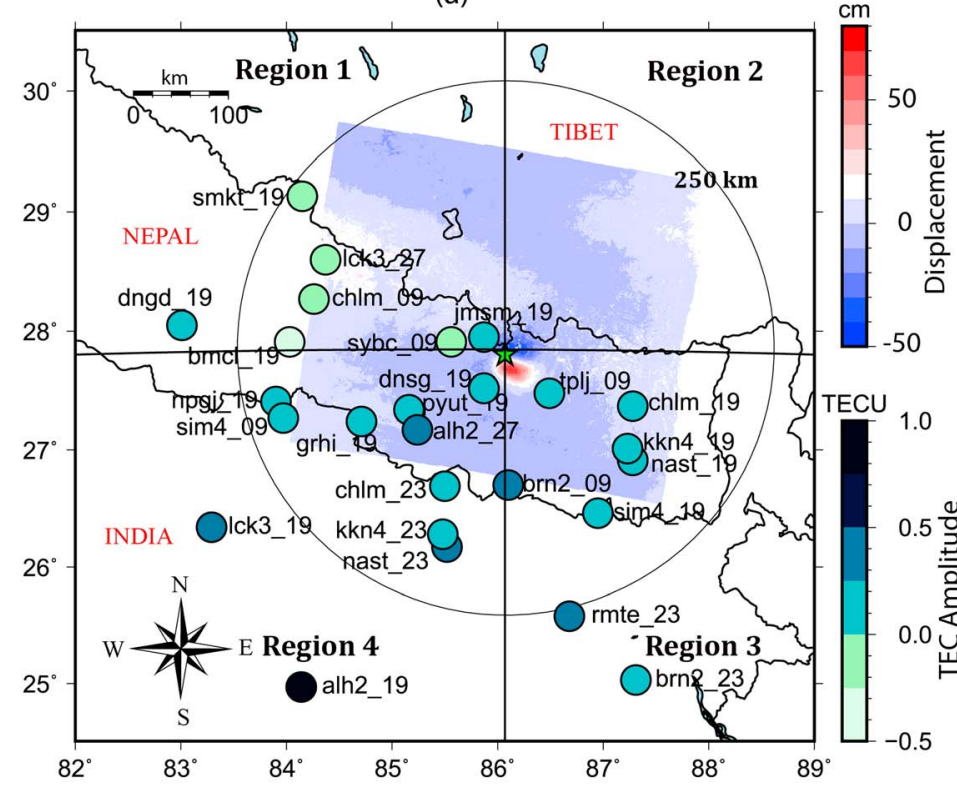

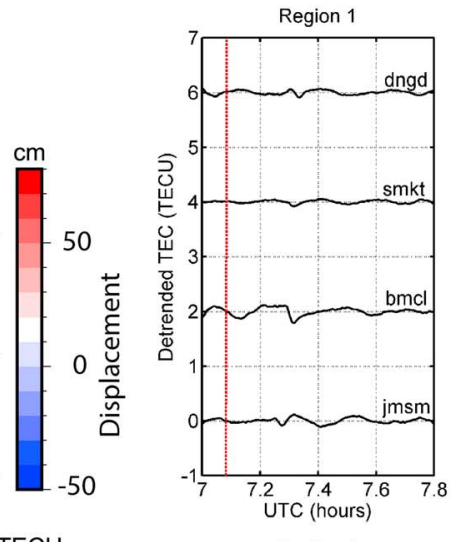

Region 1

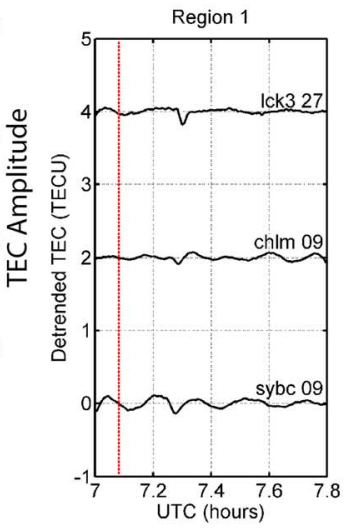

(b)
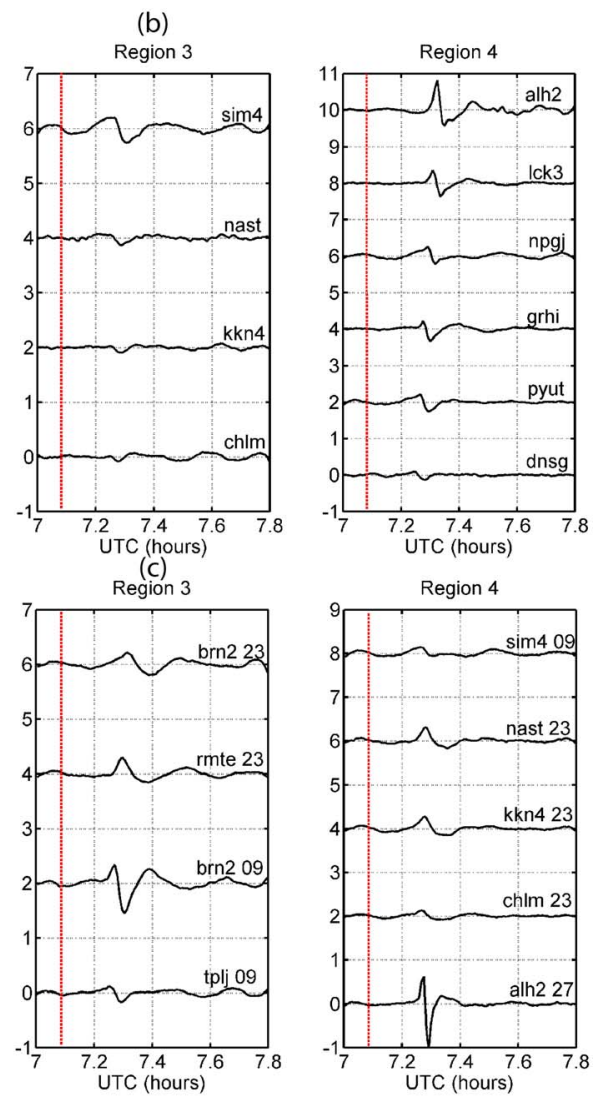

Figure 2. Near-field CIP evolution as observed by PRN 19, 09, 23, and 27. (a) IPP locations at the time of the detection of CIP in PRN 19, 09, 23, and 27. The InSAR crustal deformation image of Figure 1 is reproduced here to get the clear insight on the directionality of tectonic forcing distribution at ground and that of the CIP amplitude distribution at IPP height of $\sim 330 \mathrm{~km}$. (b) CIP evolution in TEC with time in PRN 19. (c) Same as Figure $2 \mathrm{~b}$ but for PRN 09,23, and 27.

Heki et al., 2006; Cahyadi and Heki, 2015]. The acoustic waves which propagate within zenith cutoff of $\sim 23.5^{\circ}$ over the epicenter are considered for coupling factor estimation [e.g., Heki and Ping, 2005]. More details on these could be found in the next section. The geomagnetic field inclination and declination at the epicenter are $\sim 43.4^{\circ}$ and $\sim 0.4^{\circ}$, respectively. Figure 3 shows the geomagnetic coupling factor around the epicenter. It is noticed that the geomagnetic field-wave coupling favors the CIP propagation in southern side of the epicenter (maximum factor value up to 1 ).

The epicenter being at the location around the equatorial ionization anomaly region, the effects of background ionization variability on CIP are worth to investigate here. The electron density gradient amplifies if background ionization density is high [Bagiya et al., 2013]. The background ionization is evaluated in terms of TEC maps derived using IONEX data over $12^{\circ}$ longitudes and $10^{\circ}$ latitudes around the epicenter. TEC maps at the temporal resolution of $15 \mathrm{~min}$ are reproduced in Figure 4. It can be noted that TEC gradually increases in south of the epicenter by 7:15 UTC. The gradient in background ionization is clearly larger toward south of the epicenter. Since both geomagnetic coupling factor and background ionization are favorable in south of the epicenter, any asymmetry in CIP amplitude distribution in the south could be attributed to either tectonic forcing or satellite geometry.

\section{Wave Phase Cancelation During Varying Satellite Geometry}

Figure 5 shows the acoustic wave paths derived using ray tracing method as followed from Calais et al. [1998] and Heki and Ping [2005]. The waves within $23.5^{\circ}$ zenith cutoff are observed to arrive at IPP heights of $\sim 330 \mathrm{~km}$. The wave arrival time with altitudes are shown with color codes. The quasi vertical acoustic waves with angle less than $\sim 7^{\circ}$ from the zenith discussed in Chum et al. [2016] are attributed to the horizontally traveling surface waves and observed away at distances $\sim 800 \mathrm{~km}$ from the epicenter. However, in the present study, the ray tracing is performed only for the acoustic waves which are emanating directly from the 


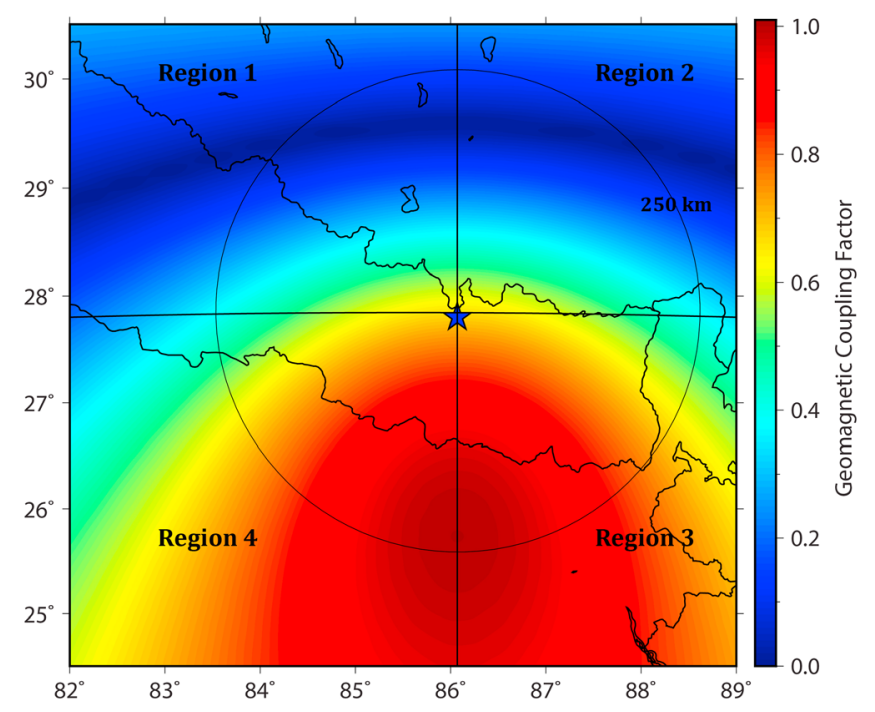

Figure 3. Geomagnetic field-acoustic wave coupling factor derived at $330 \mathrm{~km}$ height with center at the epicenter of $7.3 M_{w}$ event.

epicenter along with the coseismic surface uplift there by restricted to horizontal distances $\sim 200-300 \mathrm{~km}$. Thus, the acoustic waves by propagating surface waves that could be generated and become observable at large distances are not discussed here. It is pertinent to note that the viscosity, which becomes significant after $\sim 150 \mathrm{~km}$ altitude, affects the acoustic wave amplitudes adversely in the atmosphere. Based on Doppler sounder observations and numerical simulation, at horizontal distance of $\sim 800 \mathrm{~km}$ away from the epicenter, Chum et al. [2016] demonstrated that the oblique rays are attenuated more in comparison to quasi vertical rays because of their longer trajectories in highly viscous medium. As the focus of the present study is on near field CIP within horizontal distances of $\sim 200-300 \mathrm{~km}$ around the epicenter where acoustic waves from the epicenter are less oblique, the atmospheric viscosity effects may not be as significant.

(a)

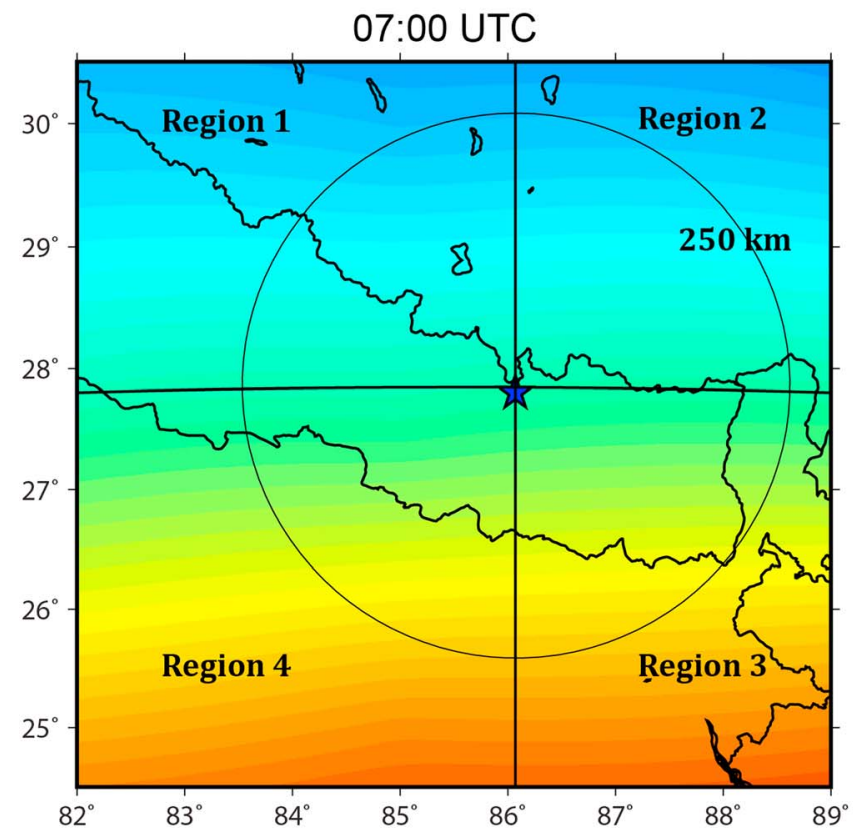

(b)

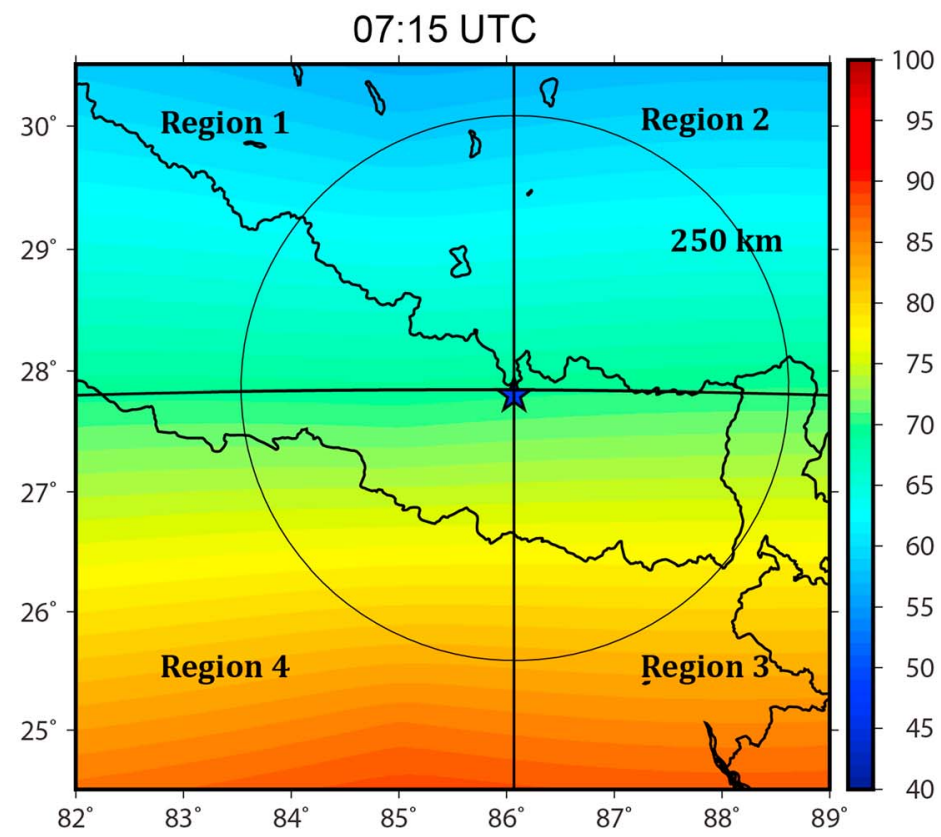

Figure 4. TEC maps derived using IONEX data over $12^{\circ}$ longitudes and $10^{\circ}$ latitudes at (a) $7.00 \mathrm{UT}$ and (b) 7.15 UT to evaluate the background ionization variability at the time of earthquake. 


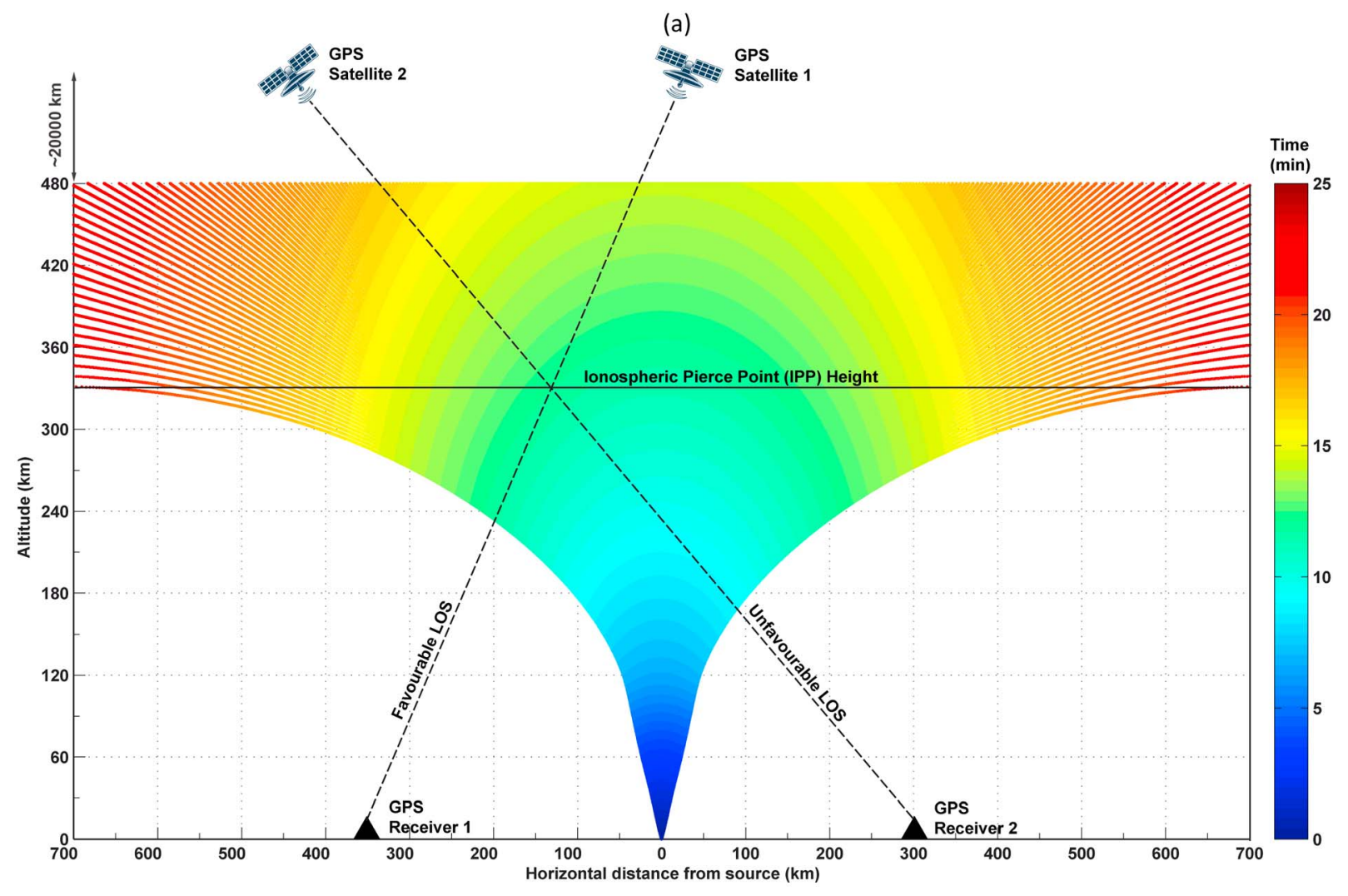

Figure 5. Wave phase cancelation effect arising from the varying satellite geometry. Acoustic raypaths from the epicenter. Schematic of two satellite-receiver pair and interaction between the acoustic wave vector and respective satellite line of sights (LOS) at $330 \mathrm{~km}$ are also shown. When the satellite LOS and acoustic wave vector are parallel to each other, i.e., wave front and LOS are perpendicular to each other the integration effect cancels the wave phases and minimize the CIP amplitudes (i.e., unfavorable LOS). In case of parallel satellite LOS and wave fronts, a satellite can observe the actual wave structure (i.e., favorable LOS).

Figure 5 also illustrates wave phase cancelation effects during varying satellite geometry along the receiver satellite LOS by showing schematic of GPS satellite-receiver pairs. It can be noticed in the figure that when the acoustic wave path and satellite LOS are parallel to each other (i.e., acoustic wave fronts and LOS perpendicular to each other), the integration of wave fronts cancels the wave phases and thus results into the minimal CIP amplitudes. On the other hand, when satellite LOS becomes perpendicular to the acoustic raypath (i.e., acoustic wave fronts and LOS parallel to each other), actual wave structure could be observed depending on geomagnetic field configuration. Georges and Hooke [1970] introduced a parameter to determine the phase cancelation contribution on CIP amplitudes arising from the satellite geometry effect. This elementary parameter is estimated, here, in terms of satellite geometry factor (SGF). For an acoustic wave with wave vector $k$ and satellite line of sight unit vector $I_{r}$ SGF is defined as follows:

$$
\mathrm{SGF}=\frac{k \cdot I_{r}}{\cos \chi}
$$

Here $k$ is the wave vector derived using ray tracing method. $\chi$ is the satellite zenith angle. The SGF is estimated at $330 \mathrm{~km}$ altitude. We mainly consider the wave phase cancelation effects on CIP amplitude during varying satellite geometry; thus, the proposed simple SGF suffices the purpose. Figure 6 a shows the distribution of acoustic wave zenith angles over the epicenter for zenith cutoff of $\sim 23.5^{\circ}$ and estimated SGF for PRN 19 along the satellite IPP tracks. The black horizontal bars in the satellite IPP tracks depict the CIP amplitudes at that location. The estimated SGF for PRNs 09, 23, and 27 is shown in Figure 6b. The SGF values are shown along the track of the satellites in Figures $6 \mathrm{a}$ and $6 \mathrm{~b}$. It is clear from Figures 5 and 6 that most favorable satellite geometry is when the wave vector $k$ and satellite line of sight $I_{r}$ are perpendicular to each other, i.e., $I_{r}$ is parallel to wave fronts and, hence, the maximum of SGF occurs with value of zero. In Figures $6 \mathrm{a}$ and $6 \mathrm{~b}$, regions 3 and 4 (same as that of Figure 2a) are in favorable geomagnetic field configuration (Figure 3) and 


\section{AGU Journal of Geophysical Research: Space Physics}

(a)

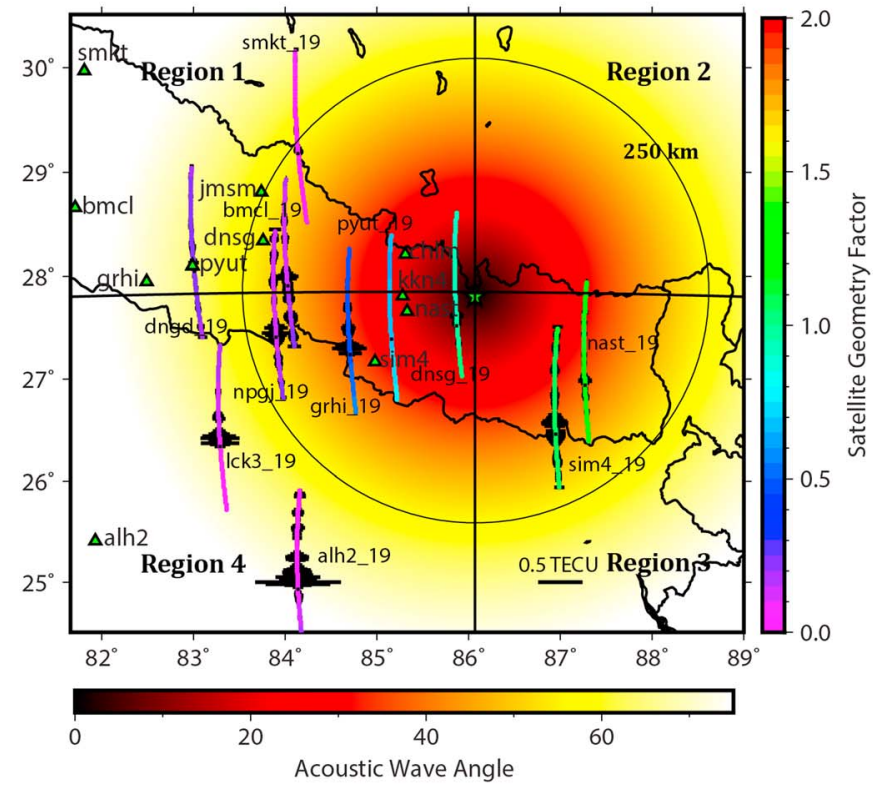

(b)

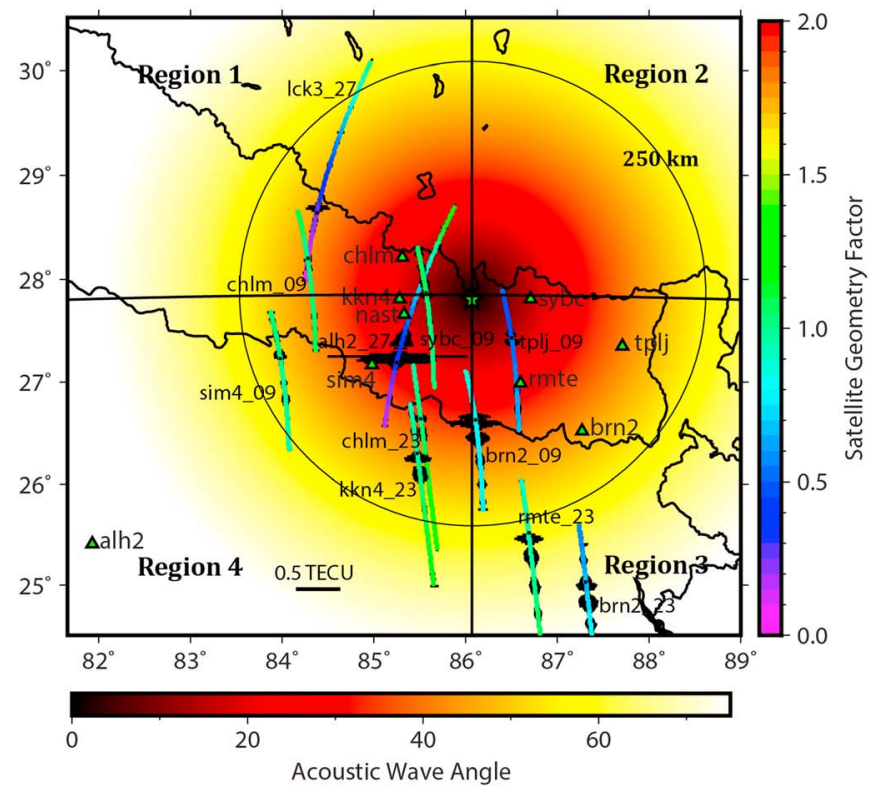

Figure 6. (a) Estimated SGF for PRN 19. The distribution of acoustic wave zenith angles over the epicenter for zenith cutoff of $\sim 23.5^{\circ}$ is reproduced in the figure. The SGF values are shown along the track of the satellite. It could be observed that phase cancelation effects are least for PRN 19 in the southwest of the epicenter with SGF values near to zero. (b) Same as Figure 6a but for PRN 09, 23, and 27. More details on this could be found in text.

also background density gradient is larger here (Figure 4). In addition, most of the tectonic energy released toward region 3 (Figure 1a), despite this maximum of CIP amplitudes, occurred in region 4 where SGF is favorable.

\section{Discussion}

A coseismic slip of $\sim 3.8 \mathrm{~m}$ at a depth of $14 \mathrm{~km}$ with an estimated $M_{w} \sim 7.31$ earthquake allows us to categorize the May 2015 Nepal event as a large thrust event. The associated surface deformation during the event varied between -0.5 and $0.75 \mathrm{~m}$ and the pattern bit elongated in south-southeast direction closely surrounding the epicenter. The maximum uplift occurred in southwest, that is, normal to the strike of coseismic slip direction. However, the rupture is more compact and circular compared to the $M_{w} 7.8,25$ April 2015 earthquake, and the surface deformations along with modeled coseismic slip indicate that most of the seismic energy was released south of the epicenter. In addition, geomagnetic field-acoustic wave coupling favors the evolution of ionospheric perturbations in southern part of the epicenter (regions 3 and 4 in Figure 2a). Thus, CIP over these regions may provide extra information on surface deformation patterns if the satellite geometry and background ionization are supportive. It could be observed that CIP in region 4 are more prominent than region 3. CIP by PRN 19 in region 4 show gradual evolution with distance in southwest from the epicenter (Figure 2b). The geomagnetic field configuration and background ionization (enhancing within $15 \mathrm{~min}$ of the event) both are favorable in this region and facilitate evolution of CIP. This is substantiated by the observed maximum amplitude in TECU ( 1.24) by alh2-19 (Figure 2b) that falls in the region of higher background ionization and maximum geomagnetic field-wave coupling. In addition, the wave phase cancelation effect is less in region 4 (Figure 6a). The SGF, Figure 6a, varies between 1 and 1.5 for PRN 19 at sim 4 and nast in region 3, while it varies between 0 and 1 in region 4 as observed from various other ground GPS stations. In Figure $6 \mathrm{~b}$ also SGF largely varies in regions 3 and 4 . Thus, it could be stated that region 3 differs from region 4 in terms of the variability of SGF. The phase cancelation effect is more pronounced in region 3 , and thus, CIP are observed with smaller amplitudes than that of region 4. In light that most rupture-induced energy propagated in south of the epicenter, our analysis of factors affecting CIP amplitude in PRN 19 reveal that the nontectonic forcing of satellite geometry is mainly dominant in region 3. Significant CIP in alh2-27 and brn2-09, in region 4, are also attributed to favorable SGF in addition to the favorable geomagnetic field-wave coupling. PRN 23 could not capture the CIP well, despite falling into favorable regions for tectonic forcing and 
geomagnetic-field wave coupling because of the intense wave phase cancelation effect as verified by SGF. However in region 1, CIP could not evolve due to poor geomagnetic field-wave coupling. We thus suggest here, through observations and presented calculations, that in addition to geomagnetic field-wave coupling, the wave phase cancelation effect due to satellite geometry also needs to be considered before tracing the ground deformation patterns through ionospheric perturbations.

\section{Conclusion}

We modeled the coseismic slip during 12 May $2015 M_{w} 7.3$ Nepal thrust earthquake and studied the nearby ionospheric response linked to the obtained deformation pattern. Aside from assessing the effect of geomagnetic field-wave coupling on CIP evolution [Rolland et al., 2013], in a step forward, we studied the effects of the wave phase cancelation on the perturbation evolution related to various receiver-satellite line-of-sight configurations invoking an elementary version of SGF. We demonstrate that the CIP could not evolve on expected lines in tandem with tectonic forcing despite favorable geomagnetic field-wave coupling, owing to wave phase cancelation effects along the receiver-satellite LOS. This illustrates that the nontectonic forcing of satellite geometry also plays a crucial role in the evolution of CIP than envisaged earlier. We believe that the present study elucidates more on the effects of nontectonic forcing mechanisms on the evolution of CIP and thus their efficiency in resolving the crustal deformation pattern. However, the addressed nontectonic effects have to be verified for CIP associated with various other earthquake mechanisms such as strike-slip and normal faulting events.

\section{Acknowledgments}

We thank UNAVCO (https://www. unavco.org/) for providing Nepal Geodetic and IGS network data. InSAR data are available at http://topex.ucsd. edu/nepal/. We acknowledge WDC for geomagnetism, Kyoto, for providing Dst and $K p$ indices. IIG GPS observations are available with PSS. This work is part of the new interdisciplinary program, Lithosphere-Atmosphere-lonosphereMagnetosphere (LAIM) coupling of Indian Institute of Geomagnetism Navi Mumbai, India. This work is supported by Department of Science and Technology (DST), India and Disaster Management Support Program of Indian Space Research Organization. ASS duly acknowledges DST, India for providing research fellowship. We are grateful to both the reviewers for their constructive comments.

\section{References}

Artru, J., T. Farges, and P. Lognonne (2004), Acoustic waves generated from seismic surface waves: Propagation properties determined from Doppler sounding observations and normal-mode modelling, Geophys. J. Int., 158, 1067-1077, doi:10.1111/j.1365-246X.2004.02377.x.

Astafyeva, E., and K. Heki (2009), Dependence of waveform of near-field coseismic ionospheric disturbances on focal mechanisms, Earth Planets Space, 61(7), 939-943, doi:10.1186/BF03353206.

Bagiya, M. S., H. P. Joshi, K. N. lyer, M. Aggarwal, S. Ravindran, and B. M. Pathan (2009), TEC variations during low solar activity period (2005-2007) near the equatorial ionospheric anomaly crest region in India, Ann. Geophys., 27(3), 1047-1057, doi:10.5194/angeo-271047-2009.

Bagiya, M. S., R. Sridharan, and S. Sunda (2013), Pre-assessment of the "strength" and "latitudinal extent" of L-band scintillation: A case study, J. Geophys. Res. Space Physics, 118, 488-495, doi:10.1029/2012JA017989.

Calais, E., J. B. Minster, M. A. Hofton, and M. A. H. Hedlin (1998), lonospheric signature of surface mine blasts from Global Positioning System measurements, Geophys. J. Int., 132, 191-202.

Chum, J., M. A. Cabrera, Z. Mošna, M. Fagre, J. Baše, and J. Fišer (2016), Nonlinear acoustic waves in the viscous thermosphere and ionosphere above earthquake, J. Geophys. Res. Space Physics, 121, 12,126-12,137, doi:10.1002/2016JA023450.

Cahyadi, M. N., and K. Heki (2015), Coseismic ionospheric disturbance of the large strike-slip earthquakes in North Sumatra in 2012: $M_{w}$ dependence of the disturbance amplitudes, Geophys. J. Int., 200, 116-129.

Georges, T. M., and W. H. Hooke (1970), Wave-induced fluctuations in ionospheric electron content-A model indicating some observational biases, J. Geophys. Res., 75, 6295-6308, doi:10.1029/JA075i031p06295.

Grawe, M. A., and J. J. Makela (2015), The ionospheric responses to the 2011 Tohoku, 2012 HaidaGwaii, and 2010 Chile tsunamis: Effects of tsunami orientation and observation geometry, Earth and Space Science, 2, 472-483, doi:10.1002/2015EA000132.

Heki, K., and J. Ping (2005), Directivity and apparent velocity of the coseismicionospheric disturbances observed with a dense GPS array, Earth Planet. Sci. Lett., 236(3-4), 845-855, doi:10.1016/j.epsl.2005.06.010.

Heki, K., Y. Otsuka, N. Choosakul, N. Hemmakorn, T. Komolmis, and T. Maruyama (2006), Detection of ruptures of Andaman fault segments in the 2004 great Sumatra earthquake with coseismic ionospheric disturbances, J. Geophys. Res., 111, B09313, doi:10.1029/ 2005JB004202.

Lindsey, E. O., R. Natsuaki, X. Xu, M. Shimada, M. Hashimoto, D. Melgar, and D. T. Sandwell (2015), Line-of-sight displacement from ALOS-2 interferometry: $M_{w} 7.8$ Gorkha earthquake and $M_{w} 7.3$ aftershock, Geophys. Res. Lett., 42, 6655-6661, doi:10.1002/2015GL065385.

Lognonne, P., E. Clevede, and H. Kanamori (1998), Computation of seismograms and atmospheric oscillations by normal-mode summation for a spherical earth model with realistic atmosphere, Geophys. J. Int., 135(2), 388-406, doi:10.1046/j.1365-246X.1998.00665.x.

National Earthquake Information Center - U. S. Geological Survey (NEIC - USGS) (2015), [Available at https://earthquake.usgs.gov.]

Okada, Y. (1985), Surface deformation due to shear and tensile faults in a half-space, Int. J. Rock Mech. Min. Sci. Geomech. Abstr., 75(4), 1135-1154, doi:10.1016/0148-9062(86)90674-1.

Otsuka, Y., et al. (2006), GPS detection of total electron content variations over Indonesia and Thailand following the 26 December 2004 earthquake, Earth Planets Space, 58, 159-165, doi:10.1186/BF03353373.

Rama Rao, P. V. S., S. Gopi Krishna, K. Niranjan, and D. S. V. V. D. Prasad (2006), Temporal and spatial variations in TEC using simultaneous measurements from the Indian GPS network of receivers during the low solar activity period of 2004-2005, Ann. Geophys., 24(12), 3279-3292, doi:10.5194/angeo-24-3279-2006.

Rolland, L. M., P. Lognonné, E. Astafyeva, E. A. Kherani, N. Kobayashi, M. Mann, and H. Munekane (2011), The resonant response of the ionosphere imaged after the 2011 off the Pacific coast of Tohoku earthquake, Earth Planets Space, 63(7), 853-857, doi:10.5047/ eps.2011.06.020.

Rolland, L. M., M. Vergnolle, J. M. Nocquet, A. Sladen, J. X. Dessa, F. Tavakoli, H. R. Nankali, and F. Cappa (2013), Discriminating the tectonic and non-tectonic contributions in the ionospheric signature of the 2011, $M_{w} 7.1$, dip-slip Van earthquake, eastern Turkey, Geophys. Res. Lett., 40, 2518-2522, doi:10.1002/grl.50544. 
Sreejith, K. M., P. S. Sunil, R. Agrawal, A. P. Saji, D. S. Ramesh, and A. S. Rajawat (2016), Coseismic and early postseismic deformation due to the 25 April 2015, $M_{w} 7.8$ Gorkha, Nepal, earthquake from InSAR and GPS measurements, Geophys. Res. Lett., 43, 3160-3168, doi:10.1002/ 2016GL067907.

Sunil, A. S., M. S. Bagiya, C. D. Reddy, M. Kumar, and D. S. Ramesh (2015), Post-seismic ionospheric response to the 11 April 2012 East Indian Ocean doublet earthquake, Earth Planets Space, 67(1), 37, doi:10.1186/s40623-015-0200-8.

Sunil, A. S., M. S. Bagiya, J. Catherine, L. Rolland, N. Sharma, P. S. Sunil, and D. S. Ramesh (2016), Dependence of near field co-seismic ionospheric perturbations on surface deformations: A case study based on the April, 252015 Gorkha Nepal earthquake, Adv. Space Res. doi:10.1016/j.asr.2016.11.041.

Wang, R. J., S. Parolai, M. R. Ge, M. P. Jin, T. R. Walter, and J. Zschau (2013), The $2011 M_{w} 9.0$ Tohoku earthquake: Comparison of GPS and strong-motion data, Bull. Seismol. Soc. Am., 103, 1336-1347, doi:10.1785/0120110264. 